\title{
Assessing the quality of routine HIV testing data in the community setting "COBATEST NETWORK"
}

Juliana Reyes-Urueña ${ }^{\mathrm{a}, \mathrm{b}, *}$, Laura Fernàndez-Lopez ${ }^{\mathrm{a}, \mathrm{b}, \mathrm{c}}$, Alexandra

Montoliu $^{\mathrm{a}, \mathrm{b}, \mathrm{c}}$, Anna Conway ${ }^{\mathrm{a}}$, Lara Tavoschi ${ }^{\mathrm{d}, \mathrm{e}}$, Irena Klavs ${ }^{\mathrm{f}}$, Lella

Cosmaro $^{\mathrm{g}}$, Isabell Eibl ${ }^{\mathrm{h}}$, Zoran Dominkovići ${ }^{\mathrm{i}}$, François Pichon ${ }^{\mathrm{j}}$, Jordi

Casabona $^{\mathrm{a}, \mathrm{b}, \mathrm{c}}$ and The COBATEST network.

${ }^{a}$ Centre d'Estudis Epidemiolòics sobre les ITS i SIDA de Catalunya (CEEISCAT),

Catalonia, Spain; ${ }^{b}$ Institute for Health Science Research Germans Trias i Pujol (IGTP),

Badalona, Spain; ${ }^{c}$ CIBER Epidemiología y Salud Pública (CIBERESP), Spain;

${ }^{d}$ European Centre for Disease Prevention and Control (ECDC), Stockholm, Sweden;

Current affiliation $^{e}$ : Department of Translational research and New Technologies in

Medicine and Surgery, University of Pisa, Pisa, Italy; ${ }^{f}$ National Institute of Public

Health, Ljubljana, Slovenia; ${ }^{g}$ Lila Milano, Italy; ${ }^{h}$ Aids Hilfe Wien, Austria; ${ }^{i}$ Iskorak -

Sexual and Gender minorities' Rights Centre, Croatia; ${ }^{j}$ The Danish AIDS Foundation,

Denmark

*Corresponding author: Juliana Reyes-Urueña, Centre for Epidemiological Studies on HIV/STI in Catalonia (CEEISCAT), Agencia de Salut Publica de Catalunya (ASPC), Generalitat de Catalunya. Hospital Germans Trias i Pujol, Ctra. de Canyet s/n. 08916 Badalona, Spain. Email: jmreyes@ iconcologia.net. Phone number: +34 93497 8931

Work count:

Abstract: 294; Text: 3400; Key words: 6 


\title{
Assessing the quality of routine HIV testing data in the community setting "COBATEST NETWORK"
}

\author{
The COBATEST network of Community Based Voluntary Counselling and \\ STI/HIV Testing (CBVCT) services was created to share similar procedures to \\ monitor the activity of CBVCT services across Europe. The network strives to \\ promote HIV testing and counselling, early diagnosis and care for hard-to reach \\ groups, however the data quality collected on these activities is unknown. The \\ aims of this study are to perform a data quality assessment from 2015 to 2016 \\ and to assess CBVCT services' data integration into the national surveillance \\ data. It performed an assessment of the functional components of data \\ management, and an evaluation of data quality based on dimensions. Half (53\%) \\ of CBVCT centres were found to have a documented organizational structure that \\ identifies roles for data management. Services that send disaggregated data have \\ no one designated to review the data quality. Overall, $82.4 \%$ (28) of the services \\ reported having instructions on how to complete the data collection. The data \\ management process is the weakest area, as just three services from the network \\ had a written procedure to address any quality error, only $35.3 \%(n=12)$ of the \\ surveyed services performed quality control and 29.4\% $(n=10)$ had an established \\ procedure to resolve any discrepancies. Of all CBVCT services, $61.8 \%(\mathrm{n}=21)$ \\ reported that the service analyses the collected data in an independent manner \\ from the network for internal purposes, $41.2 \%(n=14)$ used the information \\ generated by the COBATEST network, and $11.8 \%$ (4) made decisions based on \\ the collected data. This evaluation found that CBVCT services have reliable data \\ to support quality planning and management of the services. However, data \\ needed to be improved and quality procedures introduced to adequately translate \\ data into evidence to support further expansion of CBVCT service in the \\ EU/EEA, including the integration of CBVCT-generated data into national \\ surveillance systems.
}

Keywords: Data quality; HIV infections - diagnosis - prevention and control; Testing; Early diagnosis; Community Health Services; Europe. 


\section{Introduction}

A number of different modalities have been developed in the past decades to deliver HIV testing services to most-at-risk populations. Among these approaches, communitybased voluntary counselling and testing (CBVCT) services have been recognized as a good model to improve access to key populations by promoting early HIV diagnosis, and play an essential role in improving outcomes in the HIV care continuum, when coupled with effective linkage to care (Thornton, Delpech, Kall, \& Nardone, 2012). Given the value and contribution of HIV testing conducted in the CBVCT services towards the reduction of the undiagnosed fraction in the EU/EEA region, in 2009 the COBATEST network of CBVCT services was created with the purpose of sharing similar procedures to monitor the activity of CBVCT services across Europe to ultimately promote HIV testing and counselling, early diagnosis and care for hard-to reach groups (Fernàndez-López et al., 2016; Reyes-Urueña et al., 2015). This network was created in the context of the HIV-COBATEST project (HIV Community-based testing practices in Europe 2010-2014), and by 2016 included 41 CBVCT services from 20 different European countries (Fernàndez-López et al., 2018).

One of the main objectives of the network is to monitor and evaluate (M\&E) HIV testing activities conducted in the participating CBVTC services. To do so, a standardised protocol, including a core set of indicators to monitor HIV testing activities, has been defined and a standardized data collection form and a COBATEST web-based entry data system was created to collect and analyse the data and to make comparisons between CBVCT services possible. For participating CBVCT services unable to use the web-based entry data system, an alternative data collecting process was created whereby they could submit a minimum set of data or aggregated CBVCT 
core indicators. The information collected through the CBVCT services has proven to be of strategic value in increasing the evidence on the need for strengthening community-based service delivery models as an integral part of the HIV strategic investments, and to be used as an important source of information contributing to supporting quality services along the HIV care cascade (World Health Organization, 2015). Moreover, this strategic information should also lead to a deeper understanding of the context of the epidemic, by describing the vulnerabilities that certain communities or sub-groups face and the risks these populations are exposed to (Tavoschi \& Hales, 2016).

Taking into account the importance of the information generated from the CBVCT services and its potential utility, these data should accurately reflect what is being monitored or evaluated, and additionally should be timely and relevant. High quality data are critical for decision-making processes and for accurately assessing the impact of CBVCT services in order to maximize their effectiveness, responsiveness and cost-effectiveness. With these premises, the COBATEST network is striving to continuously improve the quality of the reported data.

Moreover, the appreciation that data collected by the COBATEST network are reliable may significantly influence how organizations respond to data, how local, national and European stakeholders perceive and value the strategic information collected by the CBVCT services, and whether these data could ultimately be integrated into formal surveillance system at national and regional levels to contribute to comprehensive monitoring of testing interventions (Tavoschi \& Hales, 2016). In this context, the aims of this study are to perform a quality assessment of the data collected by the COBATEST network from 2015 to 2016 and to assess in which degree the CBVCT services' data were integrated with the national surveillance data. 


\section{Methods}

\section{Study design and population}

A descriptive observational study was undertaken which included an assessment of the functional components of CBVCT services data management, and an evaluation of the routine COBATEST data quality based on dimensions. Data collected by the COBATEST network included information on CBVCT services' clients, their sociodemographic characteristics, risk behaviours and HIV testing results. Ethical approval was obtained from the Hospital Germans Trias i Pujol healthcare ethics committee.

\section{Assessment of the functional components of CBVCT services data management}

Each CBVCT services' manager completed a questionnaire, which was a piloted, structured ad hoc instrument hosted by the Survey Monkey website. All the CBVCT services that were partners of the COBATEST network in 2017 were invited to complete the online survey. Invitation emails were sent out on 26 April 2017, two interim email remainders were sent and the survey was closed on 03 July 2017 . The questionnaire included questions related to the main administrative and organizational CBVCT services' characteristics (typology, founding, number of people working at the CBVCT service including volunteers, settings were the CBVCT service' activities are implemented, key population targeted by the CBVCT service, type of HIV tests used, place where the confirmation of a HIV positive test is performed, type of referral procedure for HIV+ diagnosed clients and availability of staff to accompany HIV+ diagnosed clients to their first healthcare visit), as well as questions to capture six functional areas of a data management and reporting system: (1) M\&E capabilities, roles and responsibilities, (2) Indicator definitions and reporting guidelines, (3) Data collection and reporting tools and forms, (4) Data management processes, (5) Links 
with the national reporting system and (6) Data use.

\section{Assessment of quality of data based on three dimensions}

All the data collected by the COBATEST network between 01/01/2015 to 31/12/2016 were evaluated, including data collected through three possible modalities. One is a web-based data entry system that uses a standardized questionnaire and has a centralized database that allowed global and stratified analysis of pooled data from all participating centres. This system uses a unique client identification code that ensured the anonymity of the client. Disaggregated anonymized data submitted by members that use their own data entry system were also collected as were aggregated data (indicators) sent by the rest of the services. Data quality was measured using three dimensions: transcription validity; completeness and consistency.

Data Transcription validity: To measure transcription error, the number of records deemed inaccurate was divided by the number of non-empty records that should be reported according to each variable (given the questionnaire contains filter-type questions). Records were considered inaccurate if data did not conform to the syntax (format, type, range) of its definition.

Data Completeness: was measured by the number of incomplete records, divided by the number of records that should be reported according to each variable. Fields were considered incomplete if left blank and considered complete if there was a value reported.

Data Consistency: It was measured by variables that were dependent on each other and were grouped together. The number of inconsistent records in each group was divided by the total number of records. 


\section{Statistical analysis}

The descriptive analysis included the main administrative and organizational characteristics and the conflicted areas of data management and reporting system.

Differences between the two submitting groups (one was those services that use the web-based entry tool and the other those services which submit data in others formats) were assessed using Pearson's chi-squared test and Student's T test for categorical and continuous variables, respectively. This analysis was performed to compare between CBVCT services grouped by its data submission format and for the entire COBATEST dataset. A score from the 3-point answering scale was build, responses coded "N/A" or "Not Applicable," was not factored into the score. An average for all individual questions was obtained to quantify the total functional area score.

The assessment based on the analysis of three data quality dimensions was performed on the total of the CBVCT services, by year and by selected variables. In order to compare between CBVCT services and the entire COBATEST dataset, two indices were constructed from the weighted average of the proportion of correct transcriptions and completeness calculated for each variable. The first index was constructed from all COBATEST variables and the second index from the basic variables likely to be included in the core set of variables to monitor HIV testing at European level (core variables) (Tavoschi \& Hales, 2016). The weights were defined according to the degree of importance of the variable. Data analysis was performed using Stata13. CollegeStation,TX:StataCorpLP and SAS®(SAS Institute.2011).

\section{Results}

\section{Assessment of the functional components of CBVCT services data management}

Table 1 shows the number of CBVCT services participating in the network, their geo- 
distribution and the method used to send data. Thirty-four out of 39 CBVCT services responded to the survey, giving a response rate of $87 \%$. Twenty-four of 34 respondents (71\%) reported sending data to the COBATEST network through the data entry tool, two $(6 \%)$ in a disaggregated manner and five (14\%) in an aggregated manner (COBATEST indicators). Three CBVCT services (9\%) reported not being able to send data for 2016 .

Table 2 shows the assessment of the functional components of CBVCT services data management and the administrative and organizational characteristics of the participating COBATEST network services in 2017. Overall, most of the CBVCT services were based in NGOs (82.4\%), funded by a public/governmental organization or co-funded by public and/or private entities (88.3\%). The settings included NGO offices (94.1\%), outdoor settings (35.3\%), venue settings (29.4\%), health care settings $(14.7 \%)$ and others (76.5\%), including university campus, social centres and premises where prostitution commonly takes place. The primary key population in the COBATEST network was men who have sex with men (MSM) (79.4\%), followed by male sex workers (MSW) (56\%) and transsexual/transgender population (56\%).

Table 3 shows the functional components of data management and data quality from the CBVCT services of the COBATEST network, 2017. When the M\&E capabilities, roles and responsibilities were assessed overall, half (53\%) of CBVCT centres have a documented organizational structure that identifies roles for data management. More than half $(61.8 \%)$ of the centres have training plans on data management both for the staff and volunteers, $56 \%$ of the centres have someone responsible for reviewing the quality of data but just $41.2 \%$ have designated staff responsible for reviewing the quality of aggregated numbers or the digitalization of data prior to the submission. Given the small number of CBVCT services that did not use the 
data entry tool and answered the survey, the results from the assessment of the functional areas of data management and reporting were partial and considered to be not representative of the different CBVCT services. However, it was observed that services that send disaggregated data have no one designated to review the data quality and oversee the submission of data to the COBATEST Network. For services sending aggregated data, most centres $(n=4)$ had a documented organizational structure, with designated people for reviewing data quality, and among the five centres three had someone responsible for reviewing aggregated numbers prior to submission.

Overall, $82.4 \%$ (28) of the services reported having instructions on how to complete the data collection and reporting forms, and 76\% (26) provide the reporting forms to all the people working with data at the services. The data management process is the functional area seen to have the greatest weaknesses, as just three services from the whole COBATEST network had a written procedure to address any quality error, only $35.3 \%(n=12)$ of the surveyed services performed quality control and $29.4 \%$ $(n=10)$ had an established procedure to resolve any discrepancies or inconsistencies found in the datasets.

Of all CBVCT services surveyed, $61.8 \%(\mathrm{n}=21)$ reported that the service analyses the collected data in an independent manner from the COBATEST network for internal purposes, $41.2 \%(n=14)$ use the information generated by the COBATEST network, and $11.8 \%$ (4) make decisions based on the collected data. The proportion using the information and basing their decision-making on the collected data are higher among the services which are using the web-site data entry tool; $54.2 \%$ and $58.2 \%$, respectively. However, most sites use paper questionnaires, which create a double reporting method as data are captured in paper-based form and then have to be transcribed into the electronic systems. 
From the surveyed CBVCT services, just 16 centres (47.1\%) were reporting data to the national information system or national authority. It is important to bear in mind that 11 centres also belonged to the "DEVO Network", which is a network that was created in Catalonia-Spain with the help of the Regional Surveillance System. All CBVCT services surveyed, that were sending disaggregated data, and three services that were sending aggregated data, were also sending data to their national surveillance systems. Of all CBVCT services surveyed, $61.8 \%(n=21)$ reported that the service analyses the collected data in an independent manner from the network for internal purposes, $41.2 \%(n=14)$ used the information generated by the network, and $11.8 \%$ (4) made decisions based on the collected data. The percentages related to use of information and decision-making based on the collected data were higher among the services which were using the web-site data entry tool; $54.2 \%$ and $58.2 \%$, respectively. Overall, the COBATEST network assessment of data management and reporting systems showed that the scores in general are low among the five assessed functional areas (Figure 1). Those linked to the national reporting system had higher scores, however this could be explained by the fact that 11 centres belong to the "DEVO Network".

\section{Assessment of quality of data based on three dimensions}

The COBATEST network received data on a total of 95,493 clients who were tested for HIV in the participating CBVCT services/networks in 2015 and on 72,916 clients in 2016. For the individual CBVCT services/networks the number of clients varied from 8 to 43,097 in 2015 and from 7 to 38,658 in 2016.

For the all COBATEST services (39), comparing by year, it was found that data completeness remained stable in the total set of selected COBATEST variables, 
whereas among the core variables decreased slightly from $99 \%$ to $97 \%$, from 2015 to 2016 (Figure2). Transcription remained stable comparing by year in the core variables, and decreased in the whole set of variables, from $99.6 \%$ to $95.8 \%$, from 2015 to 2016. Consistency was only evaluated for the total number of variables and did not change year to year. This dimension had the lowest average (93.4\%) compared to the other dimensions. When the assessment was performed for each variable (table 3), it was found that for the core variables completeness remained stable over the study period. However, important variables such as city of the CBVCT site and date of receiving screening test result have less than $90 \%$ completeness. Regarding CBVCT core variables, those used to build the definition of migrants (year of arrival to this country and country of origin) are incomplete, the same was seen in those variables used to define type of drug injection. Important variables like: "did the client receive the screening HIV test result" and "date of receiving screening test result", had a completeness rate around $85 \%$. This low percentage of completeness might be explained by the fact that most of the COBATEST CVBCT services were using a rapid test, which means that at the moment of the clients' visit, they receive the test result. Regarding transcription, CBVCT service name and the personal identifier are variables which showed transcription issues, as many sites manually enter their names, rather than use a drop-down list.

\section{Discussion}

This assessment has identified a number of weaknesses in the data quality of the COBATEST network. These include low identification and designation of M\&E capabilities, roles and responsibilities among the CBVCT services' staff; lack of a clear written procedure to address any quality errors and procedures to resolve any 
discrepancies or inconsistencies found in the datasets; and (excluding the DEVO Network) the CBVCT services do not have clear guidance to send their data to the national/regional surveillance systems. However, in terms of transcription validity; completeness and consistency, COBATEST network data quality is high and improves over time, especially if the web-based tool is used. Therefore, the findings from this evaluation indicate that CBVCT services have reliable data to support quality planning and management of the services, though, data need to improve quality procedures in order to produce quality data to translate into evidence to support further expansion of CBVCT service in the EU/EEA, including by paving the way for CBVCT-generated data to be integrated into national surveillance systems.

Findings from this assessment have also demonstrated that among the CBVCT services, dedicating human resources to maintain data quality is a considerable challenge. This is in line with the findings of similar studies that have assessed data quality in healthcare services including community settings, that found that a workforce already burdened by service provision might set aside the quality of data (Ledikwe et al., 2014; Mate, Bennett, Mphatswe, Barker, \& Rollins, 2009). Therefore, service provision in the CBVCT services requires approaches that minimize and streamline data-related tasks, which should be centralized for long-term sustainability, be relatively low-resource and take into account the high variability of personnel in the CBVCT services. These strategies should include centralization of training and mentoring initiatives, development of Standard Operating Procedure (SOP) that clarifies staffing needs and processes for the generation and use of strategic information as well as for the set-up of standardized quality assurance processes among CBVTC services.

Strengthening electronic health information systems and harmonizing data collection systems/methods may also contribute to improve data quality. As 
computerized point-of-care CBVCT services' information (web-based data entry tool), have the potential to dramatically reduce the data collection burden by automating data aggregation and reporting (Nash D., 2009). In the context of the COBATEST network it would be advisable that all CBVCT services use the data entry tool as this will reduce error, data collection burden and allow for real-time access to data. However the findings indicate that the existing platform should be further improved and adapted to services' data needs. Data from the present assessment indicate that this potential has not yet been reached as the electronic systems in place are incomplete, lack integration and create a double reporting burden as data are often captured in both paper-based and electronic systems.

An additional, relatively high-resource investment suggested by the data in the current assessment is the harmonization of data collection in all the CBVCT services. This would include the development of essential data sets, through a timely, intensive, and consultative process for it to be effective. Such data sets would include a selection of key variables likely to be included in the core set of variables to monitor HIV testing at European level. This selection at the same time could serve the CBVCT services to fulfil their data needs in order not to represent a double burden of work for the services. Streamlining indicators and selection of a core set of variables that could be used to monitor HIV testing at European level is needed. Therefore, the COBATEST network should create a process of selection of key variables to be collected, serving both the purposes of supporting service monitoring and quality improvement process and contributing to European-level monitoring, while reducing the data collection and management burden for the CBVCT sites.

Finally, excluding the centres participating in the DEVO CBVCT services (Catalan-Spanish), the linkage of CBVCT data with the local/regional/national 
surveillance HIV systems is very limited. Some CBVCT sites describe engaging in preliminary attempts but there is no defined data process integration in place to implement it. Therefore, this is one of the tasks for the COBATEST network identified from this assessment, which will include the consolidation and expansion of the network as an important source of strategic information and the connection to national HIV surveillance systems to create this data link.

A limitation of this assessment was restricting the focus on CBVCT services participating in the COBATEST network. Despite the lack of representativeness of the COBATEST network across Europe, we believe that this network serves as a sentinel source of HIV testing information, and it is considered relevant and of added value as it provides a unique EU-level perspective. On the other hand, as participants were fully aware of the purpose of the assessment, they may have exhibited a social desirability bias, expressing to interviewers what they know are the correct policies concerning data management and reporting, rather than explaining the current procedures at their site. Despite the limitations of assessing a large quantity of data, the evaluation exercise succeeded in making a quality data analysis from different perspectives and using two data quality assessment methods.

In conclusion, this study report is a first attempt to assess the quality of routine HIV testing data in community settings and from a European perspective. We identified several gaps related to the functional components of CBVCT services data management and data quality. However, the findings showed that CBVCT services effectively collect and use quality data. This strategic information could contribute to increase the evidence on the need for strengthening community-based service delivery models as an integral part of the HIV strategic investments, and could be used as an important source 
of information contributing to support quality services along the HIV care cascade and as important information to be collected by the data surveillance systems.

\section{COBATEST network}

IP: Jordi Casabona (Centre d'Estudis Epidemiològics sobre les Infeccions de Transmissió Sexual i Sida de Catalunya: [CEEISCAT]-CIBERESP), Coordinator: Laura Fernandez (CEEISCAT), Field coordinator: Anna Conway, CBVCT services: Isabell Eibl (AIDS Hilfe Wien), Tomáš Čech, Ivo Procházka and Robert Hejzák (Czech AIDS Help Society, Prague), Zoran Dominković and Kristina Sekulic (ISKORAK), Francois Pichon (AIDS Fondet), Lionel Fugon (AIDES $†$ ), Lella Cosmaro and Sabrina Penon (Fondazione LILA Milano ONLUS), Inga Upmace (Baltic HIV Association), Loreta Stoniene (Demetra), Iwona Wawer (CBVCT centres Poland $\dagger$ ), Daniel Simoes (Checkpoint LX, IN-Mouraria and MOVE-Se), Mitja Ćosić (Legebitra), Pamela Biot, Manuel Gomez (ADHARA), Esteban Brook-Hart (AVACOS-H), Juan Ramón Barrios and Aitor Calvo (OMSIDA), Pere Salmerón (Lambda), Eva Ma Prado Cuervo (ACCAS), Sara Solier, Elena Luque (IEMAKAIE), Alexandra Pérez (CAS Gibraltar), Gema Herrero (GADES), Juan José Reyes, Sonia Reyes and Rocío García (SILOÉ), Marcela Macheras (ACAVIH), Manu de Gregorio (CASDA), Maria José Oltra (CIBE Marítim), Loly Fernández (Comité Anti-Sida Asturias (CCASiPA), Adriana Morales and Luís Villegas (STOP-SIDA), Jaime Quezadas (ACASC), Jordi Baroja (CJAS), Joaquim Roqueta and William Mejías (Gais Positius), Anna Rafel (Associació AntiSIDA de Lleida), Julia Collignon and Elena Griñán (Actuavallès), Mercè Meroño (Àmbit Prevenció), Lluís Romero and Toni Aguilar (AssexoraTgn), Anna Lara (ACAS Girona), Patrícia Colomera, Jessica Camí, Lorena Andreo and Elena Adán (SAPS-Creu Roja), Araceli Otón (Creu Roja Tarragona), Andrii Chernyshev (Alliance Global), 
Paqui Cantudo (Concordia Marbella).

\section{Acknowledgements}

We would like to acknowledge the ECDC for their support, especially Andrew Amato for his comments. We also extend our appreciation to the CBVCT services involved in the study, and to all the CBVCT services which are part of the COBATEST network, and finally our especial acknowledgement to the services' mangers who agreed to participate in the survey.

\section{Disclosure statement}

No potential conflict of interest was reported by the authors.

\section{Funding}

This work was supported by European Centre for Disease Prevention and Control (ECDC): [Service contract: ECD.6543]. The views expressed in this document do not necessarily reflect those of ECDC.

\section{ORCID}

Juliana Reyes-Urueña: https://orcid.org/0000-0002-3122-6518

Jordi Casabona: https://orcid.org/0000-0003-4816-5536

Laura Fernàndez-López: https://orcid.org/0000-0002-6353-3942

Lara Tavoschi: https://orcid.org/0000-0002-2217-4664 


\section{References}

Fernàndez-López, L., Reyes-Urueña, J., Agustí, C., Kustec, T., Klavs, I., \& Casabona, C. (2016). The COBATEST network: a platform to perform monitoring and evaluation of HIV community-based testing practices in Europe and conduct operational research. AIDS Care, 121(February), 1-5. https://doi.org/10.1080/09540121.2016.1146218

Fernàndez-López, L., Reyes-Urueña, J., Agustí, C., Kustec, T., Serdt, M., Klavs, I., ... COBATEST Network Group. (2018). The COBATEST network: monitoring and evaluation of HIV community-based practices in Europe, 2014-2016. HIV Medicine, 19, 21-26. https://doi.org/10.1111/hiv.12592

Ledikwe, J. H., Grignon, J., Lebelonyane, R., Ludick, S., Matshediso, E., Sento, B. W., ... Semo, B. werq. (2014). Improving the quality of health information: A qualitative assessment of data management and reporting systems in Botswana. Health Research Policy and Systems, 12(1), 1-10. https://doi.org/10.1186/14784505-12-7

Mate, K. S., Bennett, B., Mphatswe, W., Barker, P., \& Rollins, N. (2009). Challenges for routine health system data management in a large public programme to prevent mother-to-child HIV transmission in South Africa. PLoS ONE, 4(5), 1-6. https://doi.org/10.1371/journal.pone.0005483

Nash D., E. B. . R. M. . T. M. . S. S. . B. M. . N.-B. H. (2009). Strategies for more effective monitoring and evaluation. Journal of Acquired Immune Deficiency Syndromes, 52, 58-62.

Reyes-Urueña, J., Breveglieri, M., Furegato, M., Fernàndez-López, L., Agusti, C., \& Casabona, J. (2015). Heterogeneity of community-based voluntary, counselling and testing services for HIV in Europe: the HIV-COBATEST survey. International Journal of STD \& AIDS. https://doi.org/10.1177/0956462415623402

Tavoschi, L., \& Hales, D. (2016). Monitoring of HIV testing services in the EU/EEA. Euro Surveillance : Bulletin Europeen Sur Les Maladies Transmissibles = European Communicable Disease Bulletin, 21(48). https://doi.org/10.2807/15607917.ES.2016.21.48.30410

Thornton, A. C., Delpech, V., Kall, M. M., \& Nardone, A. (2012). HIV testing in community settings in resource-rich countries: a systematic review of the evidence. HIV Medicine, 13(7), 416-26. https://doi.org/10.1111/j.1468-1293.2012.00992.x

World Health Organization. (2015). Consolidated strategic information guidelines for HIV in the health sector. Geneva, Switzerland. Retrieved from http://www.who.int/hiv/pub/guidelines/strategic-information-guidelines/en/ 
Table 1. Community Based Voluntary Counselling and Testing services by geo localization, data submission mode and format, COBATEST network 2015-2016.

\begin{tabular}{|c|c|c|c|}
\hline $\begin{array}{l}\text { Country (region) and number of } \\
\text { CBVCT services per country }\end{array}$ & Reporting period & Data submission mode & Data format \\
\hline Austria (1 CBVCT services) & $\begin{array}{l}\text { 1.1. - 31.12.2015 } \\
\text { 1.1. - 31.12.2016 }\end{array}$ & $\begin{array}{l}\text { Data file according to } \\
\text { specification }\end{array}$ & Disaggregated \\
\hline Czech Republic (1 CBVCT services) & 1.1. - 30.6.2015 & Other: email & Aggregated \\
\hline Croatia (1 CBVCT service) & $\begin{array}{l}\text { 1.1. - 30.6.2015 } \\
\text { 1.1. - 31.12.2016 }\end{array}$ & $\begin{array}{l}\text { Data file according to } \\
\text { specification }\end{array}$ & Disaggregated \\
\hline Denmark (3 CBVCT services) & $\begin{array}{l}\text { 1.1. - 31.12.2015 } \\
\text { 1.1. - 31.12.2016 }\end{array}$ & $\begin{array}{l}\text { COBATEST web-based data } \\
\text { entry }\end{array}$ & Disaggregated \\
\hline Germany ( 1 CBVCT service) & $\begin{array}{l}\text { 1.7. - 31.12.2015 } \\
\text { 1.1. - 31.12.2016 }\end{array}$ & $\begin{array}{l}\text { Web based Excel reporting } \\
\text { form }\end{array}$ & Aggregated \\
\hline Italy (1 CBVCT service) & $\begin{array}{l}\text { 1.1. - 31.12.2015 } \\
\text { 1.1. - 31.12.2016 }\end{array}$ & $\begin{array}{l}\text { COBATEST web-based data } \\
\text { entry }\end{array}$ & Disaggregated \\
\hline Latvia (1 CBVCT service) & $\begin{array}{l}\text { 1.1. - 31.12.2015 } \\
\text { 1.1. - 31.12.2016 }\end{array}$ & $\begin{array}{l}\text { COBATEST web-based data } \\
\text { entry }\end{array}$ & Disaggregated \\
\hline Lithuania (1 CBVCT service) & $\begin{array}{l}\text { 1.1. - 31.12.2015 } \\
\text { 1.1. - 31.12.2016 }\end{array}$ & $\begin{array}{l}\text { COBATEST web-based data } \\
\text { entry }\end{array}$ & Disaggregated \\
\hline Poland (1 CBVCT service) & 1.1. - 30.6.2015 & Other: email & Aggregated \\
\hline Portugal (3 CBVCT services) & $\begin{array}{l}\text { 1.1. - 31.12.2015 } \\
\text { 1.1. - 31.12.2016 }\end{array}$ & $\begin{array}{l}\text { Web based Excel reporting } \\
\text { form }\end{array}$ & Aggregated \\
\hline Slovenia (1 CBVCT service) & $\begin{array}{l}\text { 1.1. - 31.12.2015 } \\
\text { 1.1. - 31.12.2016 }\end{array}$ & $\begin{array}{l}\text { Data file according to } \\
\text { specification }\end{array}$ & Disaggregated \\
\hline Spain (9 CBVCT services) & $\begin{array}{l}\text { 1.1. - 30.6.2015 } \\
\text { 1.1. - 31.12.2016 }\end{array}$ & $\begin{array}{c}\text { COBATEST web-based data } \\
\text { entry }\end{array}$ & Disaggregated \\
\hline Spain (4 CBVCT services) & 1.1. - 31.12.2016 & $\begin{array}{l}\text { COBATEST web-based data } \\
\text { entry }\end{array}$ & Disaggregated \\
\hline $\begin{array}{l}\text { Spain; Catalonia (Devo network - } 11 \\
\text { CBVCT services) }\end{array}$ & $\begin{array}{l}\text { 1.1. - } 31.12 .2015 \\
\text { 1.1. - 31.12.2016 }\end{array}$ & $\begin{array}{c}\text { COBATEST web-based data } \\
\text { entry }\end{array}$ & Disaggregated \\
\hline Ukraine (7 CBVCT services) & $\begin{array}{l}\text { 1.1. - 31.12.2015 } \\
\text { 1.1. - 31.12.2016 }\end{array}$ & $\begin{array}{c}\text { COBATEST web-based data } \\
\text { entry }\end{array}$ & Disaggregated \\
\hline
\end{tabular}

CBVCT services: Community Based Voluntary Counselling and Testing services 
Table 2. Administrative and organizational characteristics as well as procedures followed by the CBVCT services by data submission method, COBATEST network, 2017.

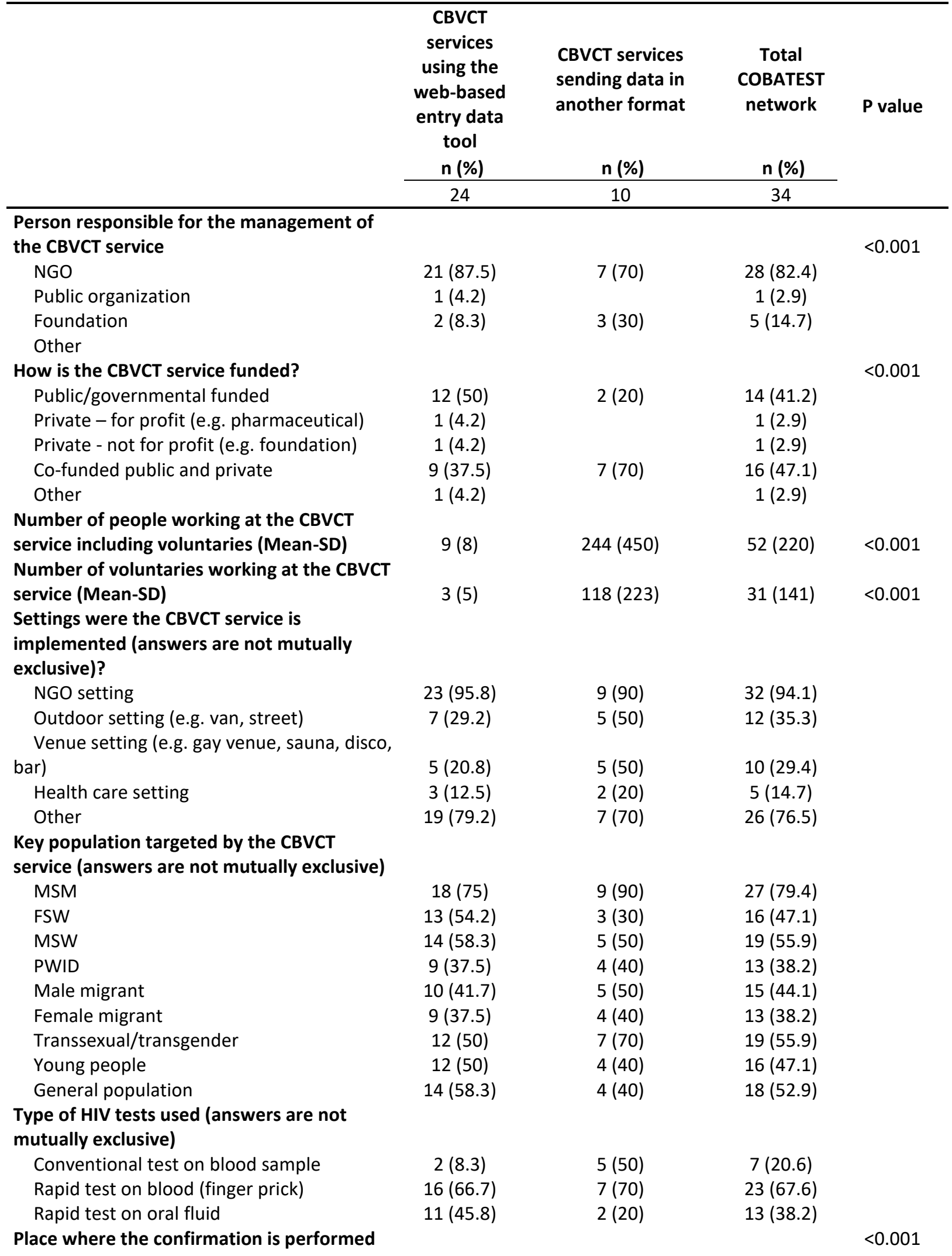




\begin{tabular}{|c|c|c|c|c|}
\hline CBVCT service & $1(4.2)$ & $1(10)$ & $2(5.9)$ & \\
\hline $\begin{array}{l}\text { A blood sample is extracted and sent to a } \\
\text { reference laboratory }\end{array}$ & $1(4.2)$ & $3(30)$ & $4(11.8)$ & \\
\hline The client is referred to a reference & & & & \\
\hline $\begin{array}{l}\text { laboratory or to a Hospital HIV unit } \\
\text { It is recommend to the client to go to a }\end{array}$ & $18(75)$ & $4(40)$ & $22(64.7)$ & \\
\hline health care centre & $2(8.3)$ & $1(10)$ & $3(8.8)$ & \\
\hline Other & $2(8.3)$ & $1(10)$ & $3(8.8)$ & \\
\hline $\begin{array}{l}\text { Referral procedure for HIV+ diagnosed } \\
\text { clients }\end{array}$ & & & & $<0.001$ \\
\hline $\begin{array}{l}\text { Clients are referred to a Hospital HIV unit } \\
\text { Clients are referred to their Primary Health }\end{array}$ & $21(87.5)$ & $7(70)$ & $28(82.4)$ & \\
\hline $\begin{array}{l}\text { Care centre } \\
\text { Clients are just informed about the Health }\end{array}$ & $2(8.3)$ & $1(10)$ & $3(8.8)$ & \\
\hline Care centres existing. & $1(4.2)$ & $1(10)$ & $2(5.9)$ & \\
\hline Other & & $1(10)$ & $1(2.9)$ & \\
\hline Accompanied visits to health care settings & & & & $<0.001$ \\
\hline Yes, always & $5(20.8)$ & & 5 (14.7) & \\
\hline The possibility is offered & $16(66.7)$ & $7(70)$ & $23(67.6)$ & \\
\hline No & $3(12.5)$ & $2(20)$ & $5(14.7)$ & \\
\hline Don't know & & $2(20)$ & 2 (5.9) & \\
\hline
\end{tabular}

CBVCT services: Community Based Voluntary Counselling and Testing services; NGO: nongovernment organization; MSM: men who have sex with men; FSW: female sex worker; MSW: male sex worker; PWID: people who injects drugs. 
Table 3. Functional components data management and data quality from the CBVCT services of the COBATEST network, 2017.

\begin{tabular}{|c|c|c|c|c|}
\hline & $\begin{array}{c}\text { Yes, } \\
\text { completel } \\
y \\
\mathbf{n}(\%) \\
\end{array}$ & n (\%) & $\begin{array}{l}\text { No, not } \\
\text { at all } \\
\text { n (\%) }\end{array}$ & $\begin{array}{l}\text { Not } \\
\begin{array}{c}\text { Applica } \\
\text { ble }\end{array} \\
\mathbf{n}(\%) \\
\end{array}$ \\
\hline \multicolumn{5}{|l|}{ M\&E capabilities, roles and responsibilities } \\
\hline $\begin{array}{l}\text { There is a documented organizational structure/chart that } \\
\text { clearly identifies positions that have data management } \\
\text { responsibilities at CBVCT service }\end{array}$ & $18(52,9)$ & $8(23,5)$ & $5(14,7)$ & $3(8,8)$ \\
\hline $\begin{array}{l}\text { There is a training plan which includes staff involved in } \\
\text { data collection and reporting process }\end{array}$ & $17(50)$ & $11(32,4)$ & $2(5,9)$ & $4(11,8)$ \\
\hline $\begin{array}{l}\text { All staff including volunteers received training on the data } \\
\text { management processes and tools }\end{array}$ & $21(61,8)$ & $8(23,5)$ & $3(8,8)$ & $2(5,9)$ \\
\hline $\begin{array}{l}\text { There is a senior staff member (e.g., the Program Manager) } \\
\text { responsible for reviewing the data sent to the COBATEST } \\
\text { network }\end{array}$ & $15(44,1)$ & $7(20,6)$ & $6(17,6)$ & $6(17,6)$ \\
\hline $\begin{array}{l}\text { There are designated staff responsible for reviewing the } \\
\text { quality of data (i.e., accuracy, completeness and } \\
\text { timeliness) }\end{array}$ & $19(55,9)$ & $8(23,5)$ & $4(11,8)$ & $3(8,8)$ \\
\hline $\begin{array}{l}\text { There are designated staff responsible for reviewing } \\
\text { aggregated numbers or the digitalization of data prior to } \\
\text { submission to the COBATEST network }\end{array}$ & $14(41,2)$ & $8(23,5)$ & $4(11,8)$ & $8(23,5)$ \\
\hline $\begin{array}{l}\text { Three is responsibility for recording the delivery of services } \\
\text { on source documents clearly assigned to specific staff o } \\
\text { member/s at the CBVCT service }\end{array}$ & $26(76,5)$ & $2(5,9)$ & $2(5,9)$ & $4(11,8)$ \\
\hline \multicolumn{5}{|l|}{ Indicator definitions and reporting guidelines } \\
\hline CBVCT service follow any data collection guidelines & $26(76,5)$ & $3(8,8)$ & $1(2,9)$ & $4(11,8)$ \\
\hline $\begin{array}{l}\text { There is a main document which describes the way to built } \\
\text { each variable or indicator measured by the CBVCT service }\end{array}$ & $18(52,9)$ & $7(20,6)$ & $6(17,6)$ & $3(8,8)$ \\
\hline $\begin{array}{l}\text { The CBVCT service use the COBATEST indicator's guidelines } \\
\text { to built the indicators measured }\end{array}$ & $18(52,9)$ & $12(35,3)$ & $2(5,9)$ & $2(5,9)$ \\
\hline $\begin{array}{l}\text { The CBVCT service share the definition of the indicator(s) } \\
\text { measured by the CBVCT service with all the people involved } \\
\text { in data collection and manipulation at the service }\end{array}$ & $18(52,9)$ & $12(35,3)$ & $1(2,9)$ & $4(11,8)$ \\
\hline $\begin{array}{l}\text { The manager has read the COBATEST indicator's guidelines } \\
\text { Data collection and reporting tools and forms }\end{array}$ & $26(76,5)$ & $5(14,7)$ & $2(5,9)$ & $1(2,9)$ \\
\hline $\begin{array}{l}\text { The CBVCT service provides standard reporting forms/tools } \\
\text { to be used by all the people working with data at the CBVCT } \\
\text { service }\end{array}$ & $26(76,5)$ & $4(11,8)$ & $2(5,9)$ & $2(5,9)$ \\
\hline $\begin{array}{l}\text { There are clear instructions on how to complete the data } \\
\text { collection and reporting forms/tools }\end{array}$ & $28(82,4)$ & $4(11,8)$ & $1(2,9)$ & $1(2,9)$ \\
\hline $\begin{array}{l}\text { Members of the CBVCT service use the documents which } \\
\text { describe indicators, data collection and reporting } \\
\text { forms/tools }\end{array}$ & $18(52,9)$ & $8(23,5)$ & $4(11,8)$ & $4(11,8)$ \\
\hline $\begin{array}{l}\text { All the main documents and reporting forms are relevant } \\
\text { for building the CBVCT service's indicator(s) available for } \\
\text { auditing purposes }\end{array}$ & $14(41,2)$ & $14(41,2)$ & $2(5,9)$ & $4(11,8)$ \\
\hline \multicolumn{5}{|l|}{ Data management processes } \\
\hline $\begin{array}{l}\text { There is at your CBVCT service a written procedure to } \\
\text { address incomplete, inaccurate, and/or missing reports }\end{array}$ & $3(8,8)$ & $5(14,7)$ & $23(67,6)$ & $3(8,8)$ \\
\hline $\begin{array}{l}\text { There are quality controls performed after the paper data is } \\
\text { entered on the computer? (e.g., double entry, post data } \\
\text { entry verification, etc). }\end{array}$ & $12(35,3)$ & $10(29,4)$ & $11(32,4)$ & $1(2,9)$ \\
\hline
\end{tabular}


If data discrepancies are identified, is there any standard procedure to document and resolve these

$10(29,4) \quad 10(29,4) \quad 11(32,4) \quad 3(8,8)$ inconsistencies

Relevant personal client data are maintained according to national or international confidentiality guidelines.

$31(91,2) \quad 1(2,9) \quad 1(2,9) \quad 1(2,9)$

There is a process to ensure proper follow up of people that have been linked to care

$10(29,4) \quad 12(35,3) \quad 6(17,6) \quad 6(17,6)$

There is a process to take into account double counting of people coming to your $\mathrm{CBCT}$ service more than once during the

$15(44,1) \quad 8(23,5) \quad 7(20,6) \quad 3(8,8)$

reporting period

Links with the national reporting system

There are data from your CBVCT service reported to the national information systems or national authority National authority showed interest in integrate the data collected by the CBVCT service into the national datasets There is any proposed initiative to integrate your CBVTC service data into the regional or national datasets

Data use

The CBVCT service's project manager and data manager have access to collected data

The CBVCT service analyses the collected data in an independent manner from the COBATEST network for internal purposes

The CBVCT service uses the information generated thought the COBATEST network tools? e.i. indicators, variables, export data, etc.

Program/service staff make decisions based on the collected data

$\begin{array}{cccc}16(47,1) & 1(2,9) & 11(32,4) & 6(17,6) \\ 12(35,3) & 8(23,5) & 9(26,5) & 5(14,7) \\ 7(20,6) & 8(23,5) & 9(26,5) & \begin{array}{c}10 \\ (29,4)\end{array} \\ 26(76,5) & 1(2,9) & 2(5,9) & 5(14,7) \\ 21(61,8) & 9(26,5) & 3(8,8) & 1(2,9) \\ & & & \\ 14(41,2) & 8(23,5) & 8(23,5) & 4(11,8) \\ 4(11,8) & 5(14,7) & 3(8,8) & (64,7)\end{array}$

CBVCT services: Community Based Voluntary Counselling and Testing services 
Table 4. Data quality index score for completeness and transcription of selected

COBATEST core variables in CBVCT services using the web-site data entry tool, by

year.

\begin{tabular}{|c|c|c|c|c|}
\hline \multirow[b]{3}{*}{ Variable } & \multicolumn{2}{|c|}{ Completeness } & \multicolumn{2}{|c|}{ Transcription } \\
\hline & 2015 & 2016 & 2015 & 2016 \\
\hline & $\%$ & $\%$ & $\%$ & $\%$ \\
\hline Name of the CBVCT site & 100 & 100 & 87.6 & 80.4 \\
\hline City of the CBVCT site & 79.3 & 78.8 & 100 & \\
\hline Type of the testing site & 100 & 100 & 100 & 100 \\
\hline Date of visit & 100 & 100 & 100 & 99.9 \\
\hline Personal identifier (CBVTC service or COBATEST identifier) & 100 & 100 & 89.4 & 91.1 \\
\hline Gender & 99.9 & 99.5 & 100 & 100 \\
\hline Date of birth & 99.4 & 99.5 & 99.8 & 99.4 \\
\hline Foreign national & 96.6 & 98.4 & 100 & 100 \\
\hline Country of birth & 97.7 & 97.3 & 100 & 100 \\
\hline Year of arrival to this country & 81.1 & 80.5 & 99.8 & 99.7 \\
\hline Is the client a resident or a tourist & 80.9 & 77.7 & 100 & 100 \\
\hline HIV test in the past & 99.7 & 99.6 & 100 & 100 \\
\hline Date of last test & 94.4 & 94.7 & 20.4 & 27.4 \\
\hline Result of last test & 97.5 & 97.0 & 100 & 100 \\
\hline HIV test in the last 12 months in this CBVCT facility & 91.8 & 94.0 & 100 & 100 \\
\hline $\begin{array}{l}\text { Sex in the last } 12 \text { months with/men/women/women and men/Any/Dont } \\
\text { know }\end{array}$ & 99.0 & 96.3 & 100 & 100 \\
\hline Condom use in the last sexual relation with penetration & 94.4 & 95.2 & 100 & 100 \\
\hline Exchange of sex for drugs or money in the last 12 months & 99.2 & 98.5 & 100 & 100 \\
\hline STI diagnosed in the last 12 months? & 94.4 & 92.2 & 100 & 100 \\
\hline Ever in jail & 86.0 & 85.0 & 100 & 100 \\
\hline Unprotected sex with penetration in the last 12 months with sex workers & 95.5 & 95.1 & 100 & 100 \\
\hline Unprotected sex with penetration in the last 12 months with PID & 95.2 & 94.7 & 100 & 100 \\
\hline $\begin{array}{l}\text { Unprotected sex with penetration in the last } 12 \text { months with known HIV } \\
\text { positive partner }\end{array}$ & 95.4 & 95.0 & 100 & 100 \\
\hline Unprotected sex with penetration in the last 12 months with MSM & 95.7 & 95.1 & 100 & 100 \\
\hline Are you an intravenous drug use? & 99.5 & 98.5 & 100 & 100 \\
\hline Date of last time of injection & 75.4 & 73.9 & 83.7 & 84.1 \\
\hline Share of materials of injection in the last 12 months, as: Syringes or needles? & 77.9 & 73.9 & 100 & 100 \\
\hline Share of materials of injection in the last 12 months, as: Spoons, filters; water & 77.9 & 73.0 & 100 & 100 \\
\hline Pre-test/pre-result counselling performed & 96.1 & 95.5 & 100 & 100 \\
\hline Date of specimen collection, screening HIV test & 99.6 & 99.9 & 96.6 & 96.4 \\
\hline Type of test used & 99.9 & 100 & 100 & 100 \\
\hline Reason for HIV testing & 97.8 & 97.9 & & \\
\hline Screening test result & 99.9 & 99.9 & 99.2 & 99.5 \\
\hline Did the client receive the screening HIV test result & 80.0 & 77.5 & 100 & 100 \\
\hline Date of receiving screening test result & 86.3 & 84.7 & 96.0 & 96.2 \\
\hline Post-test HIV counselling performed & 96.2 & 92.3 & 100 & 100 \\
\hline Confirmatory test performed & 93.3 & 97.8 & 100 & 100 \\
\hline Date of specimen collection for the confirmatory HIV test result & 40.9 & 63.0 & 98.1 & 95.4 \\
\hline Confirmatory HIV test result & 98.4 & 96.4 & 100 & 100 \\
\hline Did the client receive the confirmatory HIV test result & 60.6 & 65.9 & 100 & 100 \\
\hline Date of receiving confirmatory test result & 34.6 & 47.8 & 97.7 & 95.5 \\
\hline Patient was linked to healthcare system & 79.8 & 76.6 & 100 & 100 \\
\hline Date of linkage & 48.2 & 60.3 & 92.7 & 91.8 \\
\hline First $C D 4$ count result & 31.6 & 27.3 & 100 & 100 \\
\hline
\end{tabular}


Index of variables likely to be included in the core set of variables to

90.3

96.0

95.8
monitor HIV testing at European level

- Proposed core variables to monitor HIV testing at European level 
Figure 1. Score for each one of the functional components of data management and data quality for the overall COBATEST Network Assessment, 2017.

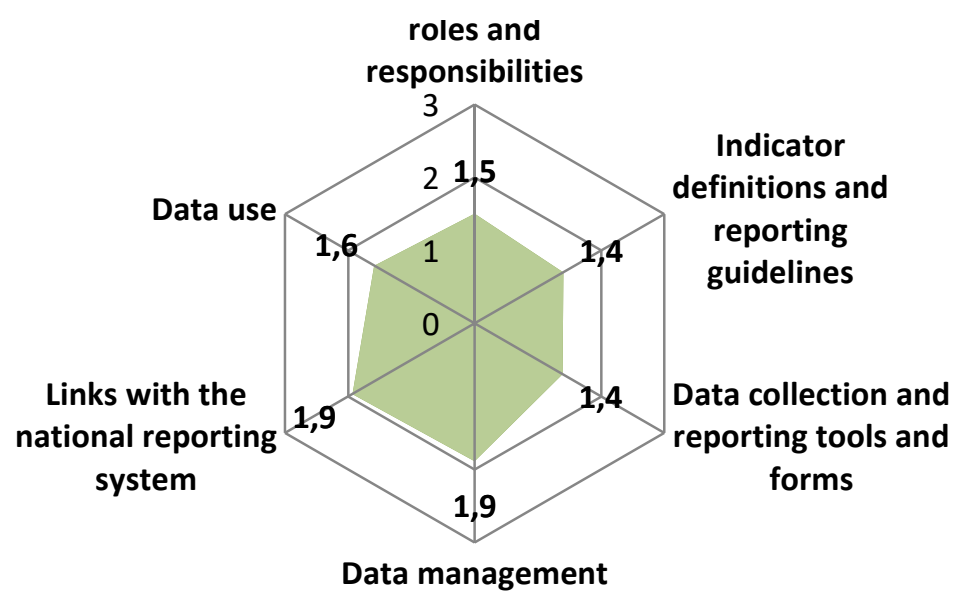


Figure 2. Completeness, transcription and consistency by selected core variables for the COBATEST network and for the basic variables likely to be included in the core set of variables to monitor HIV testing at European level, 2015-2016.

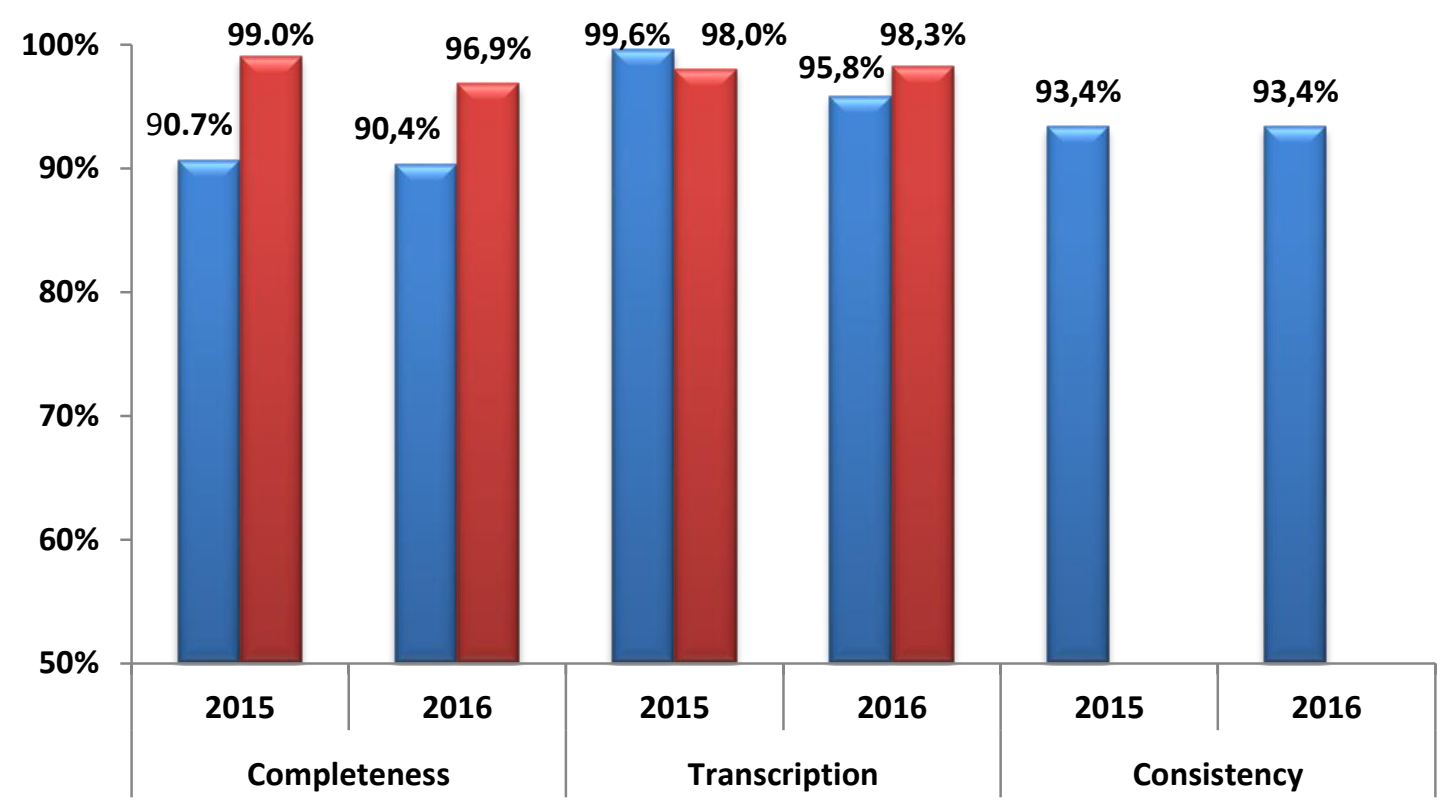

